\title{
Evaluation of Trace Metals in Superficial Sediments of Parnaíba River Delta, Brazil
}

\author{
THAYS THAYANNE LUZ SANTOS ${ }^{12 *}$, ROZANE VALENTE \\ MARINS $^{1}$ AND JEAN LOUIS STEPHANE MOUNIER ${ }^{2}$ \\ ${ }^{1}$ Federal University of Ceará, Marine Science Institute, Av. da \\ Abolição, 3207 - Meireles, Fortaleza - CE, 60165-081, Brazil \\ (*correspondence: thays_luzsantos@hotmail.com, \\ rozanemar@gmail.com) \\ ${ }^{2}$ Université de Toulon, Mediterranean Institute of Oceanography, CS \\ 6058483041 - Toulon, France (stephane.mounier@univ-tln.fr)
}

Natural metal concentrations in delta systems, even in remote areas, can be enriched by discharges of domestic and agricultural effluents and navigation. Studies on the assessment of sediment quality are essential sources of information on environmental contamination. The present study aims to determine the spatial distribution and to assess the state of trace metal contamination based on a sediment quality index. Surface sediment samples were collected in Parnaíba Delta, the largest open sea deltaic formation in the Americas at the Equatorial coast of Brazil. Sediments were oven-dried at $60^{\circ} \mathrm{C}$, powdered, and sieved to determination of grain-size and trace metals quantification ( $\mathrm{Al}, \mathrm{Fe}, \mathrm{Mn}, \mathrm{Cr}, \mathrm{Cu}$, $\mathrm{Pb}, \mathrm{Ni}$ and $\mathrm{Zn}$ ) in the fraction $<63 \mu \mathrm{m}$ [1]. Geoaccumulation index (Igeo) was determined to evaluate the potential anthropogenic contamination. Surface sediment grain-size showed the predominance of medium sand indicating a high local hydrodynamic environment, but brokered by local with fine sand deposition. The distribution of trace metal indicated that grain size, sources and intrinsic properties of metals generate a varied distribution of these elements along the delta. Igeo exhibited unpolluted values for $\mathrm{Al}, \mathrm{Fe}, \mathrm{Mn}, \mathrm{Cr}$ and $\mathrm{Ni}$, but anomalous values for $\mathrm{Pb}, \mathrm{Zn}$ and $\mathrm{Cu}$, which classified the sediment in most station as moderately to strongly polluted by $\mathrm{Pb}$ (Class 3), and moderately polluted by $\mathrm{Zn}$ and $\mathrm{Cu}$ at least in one station by (Class 2), in agreement with a previous study in the same area [2]. $\mathrm{Zn}$ and $\mathrm{Cu}$ can act as essential micronutrients for most aquatic organisms' metabolism, but $\mathrm{Pb}$ is known to be non-essential and toxic and can cause physiological damage [3]. So, these results suggest low antropogenic contribution for most trace metals, except $\mathrm{Pb}$ that presents the highest anomalous values in the sediment which may present a potential risk to the environment.

[1] Aguiar et al. (2007). Geochimica Brasiliensis, 21 (3), 304-323. [2] Paula Filho et al. (2019). Actas de la V Reunión Argentina de Geoquímica de la Superficie 5, 138-141 [3] Góngora-Gómez et al. (2017). Hidrobiológica 27, 219-227. 